\title{
CARACTERIZAÇÃO MORFOLÓGICA DE FRUTOS, SEMENTES E PLÂNTULAS DE Pseudima frutescens (Aubl.) Radlk. (SAPINDACEAE) ${ }^{1}$
}

\author{
ADELITA APARECIDA SARTORI PAOLI ${ }^{2}$, ANDRÉ BIANCONI $^{3}$
}

\begin{abstract}
RESUMO - Este estudo descritivo procurou elucidar aspectos morfoanatômicos e do desenvolvimento dos frutos, sementes e plântulas de Pseudima frutescens (Sapindaceae), uma espécie arbórea. Nas descrições foram utilizados flores e frutos em diferentes estádios de desenvolvimento e, para a observação da germinação e do desenvolvimento das plântulas, as sementes foram colocadas para germinar sobre papel de filtro umedecido com água destilada, em caixas de plástico transparente, com tampa, utilizando-se amostras de 100 sementes (quatro sementes por caixa), mantidas em temperatura de $25 \pm 1^{\circ} \mathrm{C}$. O fruto desta espécie, com duas sementes, é uma cápsula obcordada circundante, lobada, de coloração laranja-avermelhada externamente e laranja internamente. A semente, exalbuminosa, é ovóide, preta e brilhante; o embrião ocupa todo o interior da semente e possui cotilédones carnosos e eixo hipocótilo-radícula curto. A plântula é criptocotiledonar e a germinação, que é hipógea, ocorre na presença de luz, iniciando no quinto dia após a semeadura. Com oito dias, a raiz primária media 17 mm de comprimento, apresentando-se coberta de pêlos absorventes. Após 14 dias emergiu o epicótilo de coloração esverdeada. A plântula apresenta, após 30 dias, dois pares de eófilos compostos. Com 60 dias, a raiz principal media $12 \mathrm{~cm}$ de comprimento, com muitas raízes laterais e o epicótilo com 9 cm de extensão possuía seis folhas expandidas. Como o desenvolvimento da plântula é relativamente rápido, $P$. frutescens pode ser uma espécie indicada para programas de recuperação de áreas degradadas.
\end{abstract}

Termos para indexação: morfologia, anatomia, germinação.

\section{MORPHOLOGICAL CHARACTERIZATION OF FRUITS, SEEDS AND SEEDLINGS OF Pseudima frutescens (Aubl.) Radlk. (SAPINDACEAE)}

\begin{abstract}
The present descriptive study aimed to elucidate the morphoanatomical and developmental features of fruits, seeds and seedlings of Pseudima frutescens (Sapindaceae), which is a tree species. Flowers and fruits at different developmental stages were used in the descriptions. A hundred seeds were set in germination boxes (four seeds per box) on filter paper moistened with distilled water and kept at $25 \pm 1^{\circ} \mathrm{C}$ to observe seedling germination and development. The fruit of this species, which has two seeds, is a round obcordate capsule, lobed, reddish-orange on the outside and orange on the inside. The seed exalbuminous, is ovoid, black and shiny; the embryo, occupying all the inside of the seed, has fleshy cotyledons and a short hypocotyl-radicle axis. The seedling is cryptocotyledonary and the germination, which is hypogeal, occurred under light conditions and
\end{abstract}

\footnotetext{
${ }^{1}$ Submetido em 17/08/2007. Aceito para publicação em 28/04/2008. ${ }^{2}$ Professora Adjunta, Departamento de Botânica/Instituto de Biociências/ Universidade Estadual Paulista (IB-UNESP), Avenida 24-A, nº1.515, Caixa Postal 199, CEP: 13506-900, Rio Claro-SP, aapaoli@rc.unesp.br
}

\footnotetext{
${ }^{3}$ Ecólogo, aluno do Programa de Pós-graduação em Ciências Biológicas (Biologia Vegetal); Departamento de Botânica/IB-UNESP,Rio Claro-SP; drebianconi@yahoo.com.br
} 
started from the fifth day after sowing. By the eighth day, the root measured $17 \mathrm{~mm}$ in length, showing numerous absorbent hairs on its full extent. After 14 days, the epicotyl (slightly green) emerged. The seedling exhibited, after 30 days, two pairs of compound eophylls and, by the sixtieth day, the primary root measured $12 \mathrm{~cm}$ long with many lateral roots; the epicotyl was $9 \mathrm{~cm}$ long and had six expanded leaves. In view of the fact that the development of the seedling is considered relatively quick, $P$. frutescens may be indicated for the use in the recovery of degraded areas.

Index terms: morphology, anatomy, germination.

\section{INTRODUÇÃO}

O conhecimento das estruturas morfoanatômicas de frutos, sementes e plântulas é importante na paleobotânica, na arqueologia, na fitopatologia, no estudo de comunidades vegetais, na identificação e na diferenciação de espécies, no reconhecimento da planta no campo, na taxonomia e na silvicultura e, mais recentemente, na análise de sementes para agricultura e horticultura, cujos processos envolvem conhecimentos de fisiologia vegetal (Gunn, 1972; Bravato, 1974; Beltrati, 1994).

As sementes possuem características básicas para a identificação de famílias, gêneros ou até mesmo espécies. O estudo das características morfoecológicas das sementes, para a produção de mudas visando à recuperação de áreas degradadas, é importante para a manutenção da biodiversidade (Oliveira et al., 2006) e o êxito na formação de florestas depende, em grande parte, da qualidade das mudas plantadas, que além de terem de resistir às condições adversas no campo, deverão sobreviver e se desenvolver (Gomes et al., 1991). Assim, informações básicas sobre a morfoanatomia e fisiologia das sementes são fundamentais para o plantio de espécies em geral.

Na Taxonomia Vegetal, até pouco tempo atrás, apenas os caracteres da planta adulta eram utilizados e as características das plântulas eram pouco exploradas (Barroso et al., 1999). Atualmente, é aceito que os trabalhos taxonômicos não devem ser baseados apenas nos caracteres morfológicos de espécimes adultos. O estudo morfológico das plântulas, em sua primeira fase de desenvolvimento, antes da produção das folhas definitivas, permite a descoberta de estruturas transitórias primitivas ou derivadas que desaparecem com o desenvolvimento da planta, mas que podem ter extraordinária importância para se estabelecerem relações de parentesco ou conexões filogenéticas com grupos, cujos órgãos adultos apresentem essas características (Ricardi et al., 1977; Torres, 1985). Segundo Finger (1977), o conhecimento das fases iniciais das plantas é recomendado, não apenas com propósitos taxonômicos, filogenéticos ou ecológicos, mas por representarem contribuições ao conhecimento global da espécie.

Estudos morfoanatômicos dos frutos podem ser de fundamental importância para a separação de gêneros, além de fornecerem informações básicas para o uso de espécies em futuros programas de recuperação de áreas degradadas. Na natureza, vários fatores contribuem para a variabilidade da forma e do tamanho de frutos e sementes. Vários autores salientam a importância dos caracteres morfoanatômicos dos diásporos, uma vez que o tamanho dessas estruturas é indispensável para que se possa conhecer melhor determinada espécie (Raven et al., 2001). Barroso et al. (1999) afirmam que o tamanho e a forma do fruto e o seu tipo de deiscência são caracteres imprescindíveis para a classificação destes, salientando que os estudos morfológicos de frutos contribuem para a identificação das espécies, bem como para a análise de sua distribuição geográfica e interações com a fauna.

Sapindaceae compreende 120 gêneros com mais de 1.000 espécies, distribuídas por todos os trópicos (Reitz, 1980; Schultz, 1985; Lorenzi, 1992). Dentre estas, destaca-se Pseudima frutescens, uma espécie arbórea com aproximadamente cinco metros de altura, conhecida vulgarmente como fruta-anel. Suas flores são apícolas e a planta, considerada pioneira e de rápido crescimento, é recomendada para reflorestamentos heterogêneos com objetivos ecológicos.

Sendo assim, o objetivo deste trabalho foi elucidar aspectos morfoanatômicos e do desenvolvimento de frutos, sementes e plântulas de $P$. frutescens.

\section{MATERIAL E MÉTODOS}

O material botânico de Pseudima frutescens (Aubl.) Radlk. constou de flores e de frutos em diferentes estádios de desenvolvimento. O material foi coletado em indivíduos situados nos arredores do Campus de Rio Claro/UNESP e transportados em sacos de plástico para o Laboratório 
de Anatomia do Instituto de Biociências/UNESP. No laboratório, o material foi examinado a fresco e as medições individuais dos frutos e das sementes foram efetuadas em amostras de 50 unidades com auxílio de um paquímetro, sendo posteriormente calculadas as médias.

Para a descrição morfológica dos frutos e das sementes foram observados detalhes externos e internos, referentes à textura, consistência, cor, pilosidade, brilho, forma, deiscência e número de sementes por fruto, posição do hilo, da micrópila e tipo de embrião.

Para o estudo anatômico dos frutos e das sementes em diferentes estádios de desenvolvimento, foram efetuadas secções transversais, longitudinais e paradérmicas, à mão livre, com auxílio de lâmina de aço inoxidável ou utilizandose micrótomo rotativo. Na obtenção de lâminas semipermanentes, as secções realizadas à mão livre foram coradas com safrablau (Milaneze, 1992) e montadas em gelatina glicerinada. As lâminas permanentes foram confeccionadas com peças fixadas e o material incluído em glicol metacrilato, seguindo-se a técnica descrita por Guerrits (1991). O material foi seccionado em micrótomo rotativo manual, as secções coradas com azul de toluidina a $0,05 \%$ e em tampão acetato de pH 4,7 (Feder e O’Brien, 1968), sendo montadas em resina sintética.

Para observação da germinação e do desenvolvimento das plântulas, as sementes foram colocadas para germinar sobre papel de filtro umedecido com água destilada, em caixas de plástico ("gerbox"). Foram utilizadas amostras de 100 sementes por tratamento (quatro sementes por caixa), mantidas em temperatura de $25 \pm 1^{\circ} \mathrm{C}$. Para o acompanhamento do desenvolvimento das plântulas, estas foram posteriormente transferidas para viveiro, em sacos de plástico, utilizando-se o substrato Plantmax ${ }^{\circledR}$.

O termo plântula, neste trabalho, foi utilizado para designar o desenvolvimento pós-seminal até o aparecimento e completa expansão do primeiro eófilo, e planta jovem, para a fase seguinte, até o surgimento do primeiro metáfilo.

As ilustrações referentes à morfologia do fruto, semente e plântula foram obtidas com uso de estereomicroscópio com uma câmara clara adaptada. As fotomicrografias referentes aos aspectos anatômicos dos frutos e das sementes foram obtidas com auxílio de um fotomicroscópio Olymphus e as ilustrações com câmara clara acoplada ao microscópio.

\section{RESULTADOS E DISCUSSÃO}

As flores de $P$. frutescens são reunidas em inflorescências do tipo panícula terminal. São actinomorfas, com sépalas (4 ou 5) e pétalas (5) unidas na base, com mais ou menos oito estames com anteras oblongas, basifixas. O ovário é central, trilocular, tricarpelar, com um a dois óvulos por lóculo. O fruto é uma cápsula obcordada circundante, lobada, de coloração laranja-avermelhada na face externa e laranja na face interna, apresentando duas sementes e medindo cerca de 2,5 x 4,5 x 2,2cm. A semente é ovóide, preta, brilhante e mede cerca de 1,8 x 1,6 x 1,5cm. O funículo, de coloração amarela, é curto e engrossado. O hilo é envolvido por um arilo de coloração amarelada. A semente é exalbuminosa, possui embrião que ocupa todo o interior da semente, com cotilédones carnosos e eixo hipocótilo-radícula curto (Figura $1 \mathrm{~A}-\mathrm{G})$.

Sapindaceae é geralmente constituída por indivíduos que, nos diferentes hábitats, apresentam grande variabilidade em detalhes estruturais nos órgãos vegetativos, nos frutos e nas sementes, contrastando com a uniformidade das flores, que são pequenas (Corner, 1976). De acordo com Reitz (1980) e Barroso et al. (1999), existe grande variabilidade em relação aos frutos e às sementes, ocorrendo sementes ariladas, exariladas, sarcotestais, aladas, de coloração variada e frutos de diferentes tipos, como cápsula, baga, drupa e sâmara. Assim sendo, a dificuldade na identificação de espécies pode ser amenizada através do conhecimento da estrutura e do desenvolvimento anatômico.

O arilo é citado em trabalhos sobre sementes de espécies que possuem frutos capsulares e, notavelmente, com coloração vermelha e amarela, associado à exotesta coriácea de coloração marrom a preta, enquanto que a ausência de arilo fica restrita a sementes de frutos indeiscentes ou de cápsulas papiráceas (Corner, 1976).

Paoli e Sarti (2008) trabalhando com frutos e sementes de Dodonea viscosa (Sapindaceae), observaram frutos capsulares, alados, sementes ovóides de coloração preta e presença de arilo vestigial amarelado, concordando com os relatos de Corner (1976). As sementes de P. frutescens enquadram-se também, neste contexto, pois apresentam coloração preta, são globosas, possuem arilo e os frutos são capsulares de coloração laranja-avermelhada.

Roosmalen (1985) relatou para Sapindaceae a ocorrência de frutos tipo cápsula (Cupania, Dodonea, Matayba, Paullinia, Pseudima, Vouarana), baga (Talisia) ou esquizocarpo (Allophyllus, Sapindus, Serjania, Thinouia, Toulina, Urvillia). Nacif et al. (2001) estudando os aspectos morfoanatômicos do desenvolvimento do fruto de Litchi chinensis (Sapindaceae), descreveram o fruto como sendo uma drupa, entretanto com endocarpo membranáceo, em 
contraste com a maioria das drupas típicas. Segundo Roth (1977), drupas típicas, freqüentemente, possuem endocarpo lignificado constituindo o pirênio (caroço) e são considerados frutos altamente especializados.

FIGURA 1. A. Ramo de Pseudima frutescens. B. Inflorescência. C. Flor. D-E. Detalhe do fruto maduro. F. Aspecto externo da semente. G. Embrião
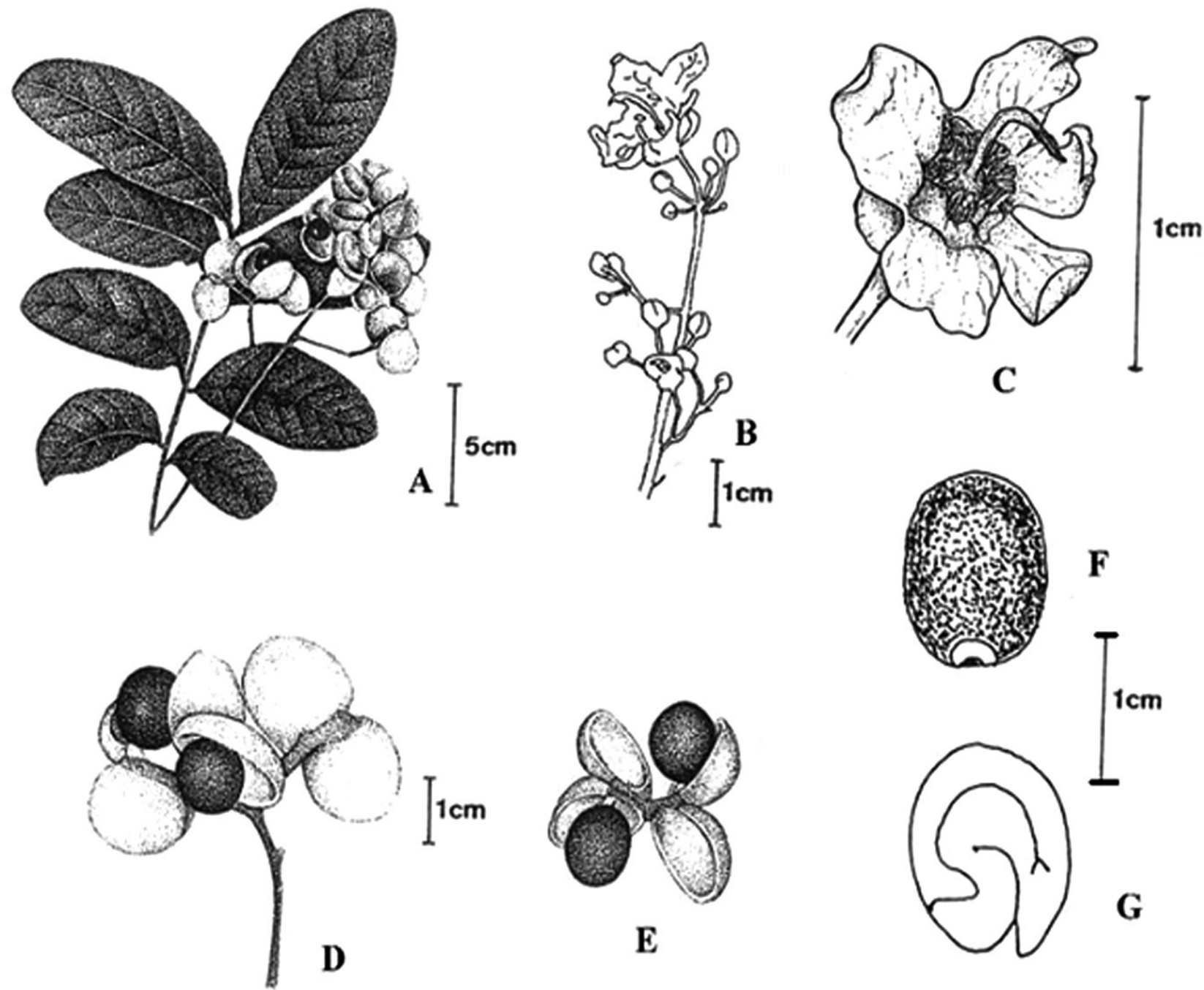

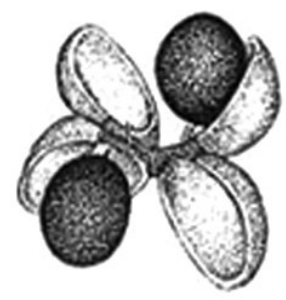

E

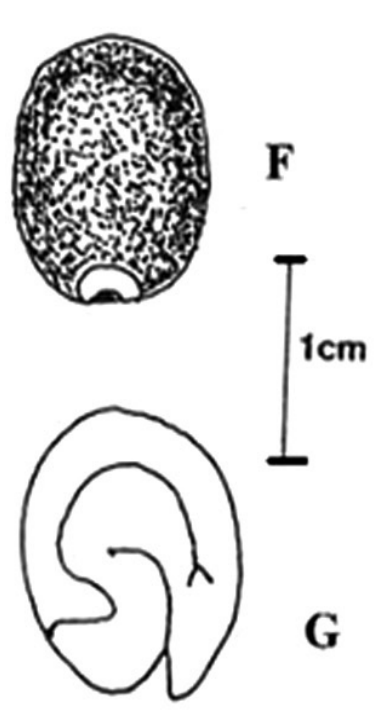

Spjut (1994) englobou os frutos de Sapindaceae, em geral, como baga, sâmara, câmara e cápsula loculicida, porém este autor não trabalhou com Pseudima sp. De acordo com a classificação de Barroso et al. (1999) o fruto é uma cápsula circundante, cuja abertura inicia-se a partir da base, nas porções laterais.

Com relação à anatomia do fruto, observou-se, no fruto bem jovem (Figura 2A), epiderme externa unisseriada com estômatos e tricomas pluricelulares, estrelados; uma região parenquimática com feixes vasculares, idioblastos com drusas e epiderme interna unisseriada. Num estádio mais desenvolvido, porém ainda imaturo (Figura 2B), o epicarpo apresentou-se com epiderme externa unisseriada; o mesocarpo com 3 ou 4 camadas de células de paredes um tanto espessadas, lignificadas, seguidas por várias camadas de células parenquimáticas, onde ocorrem feixes vasculares e idioblastos contendo cristais do tipo drusa, e endocarpo com uma única camada de células de cutícula delgada. O fruto maduro (Figura 3A-C) apresentou mais camadas (4 a 6) de células com paredes espessadas, lignificadas, e, entre as células parenquimáticas do mesocarpo, grupos de esclereídes e feixes vasculares mais desenvolvidos. 
FIGURA 2. Fruto de Pseudima frutescens em seção transversal. A. Fruto bem jovem. B. Fruto mais desenvolvido, mas ainda imaturo.
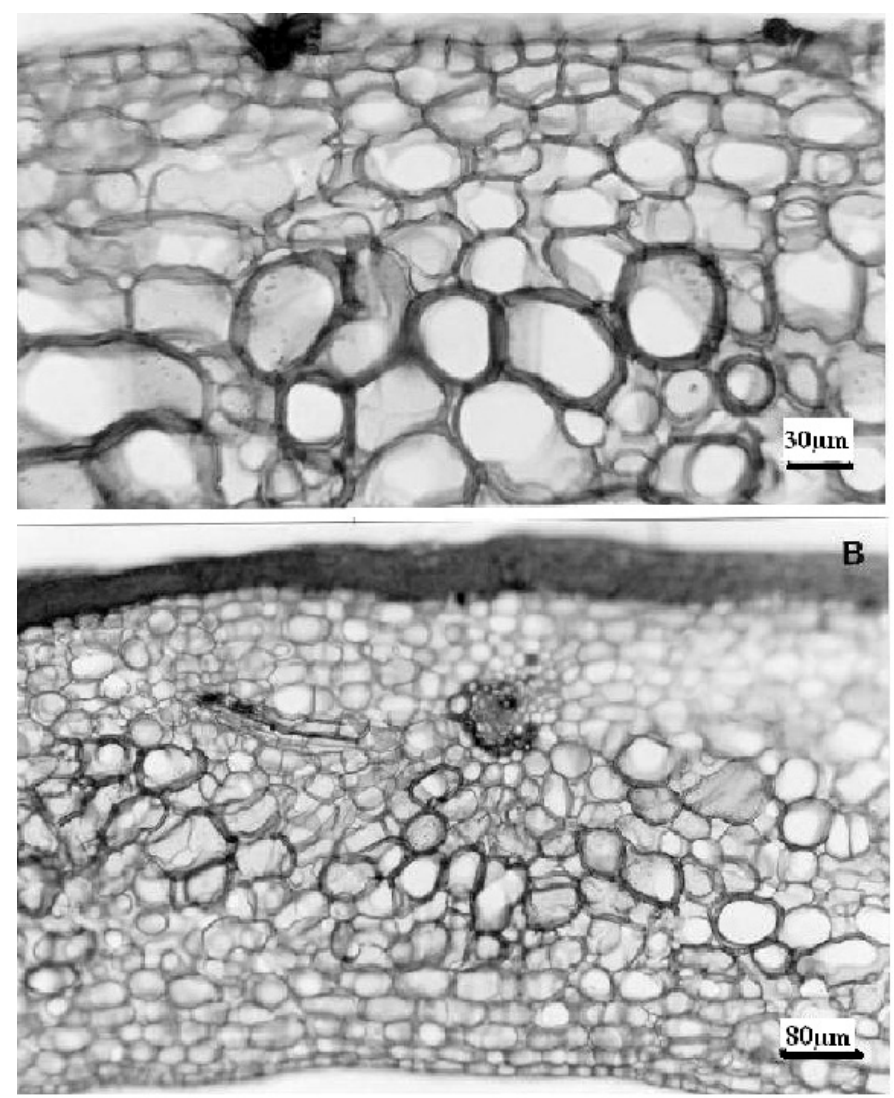

O padrão estrutural do fruto de $P$. frutescens, mostrouse semelhante ao observado para Litchi chinensis e para Dodonea viscosa, com fibras no epicarpo, mesocarpo parenquimático (carnoso) e endocarpo membranáceo (Nacif et al., 2001; Paoli e Sarti, 2008).

Com relação ao número de óvulos no ovário, Sapindaceae possui representantes com apenas um óvulo ereto ou ascendente em cada lóculo e representantes com dois ou mais óvulos em cada lóculo do ovário. No segundo caso, é freqüente o aborto de um deles; de modo que o fruto apresenta-se monospermo, como em Dodonea e Koelrenteria e nos bacóides de modo geral (Barroso et al., 1999).

A semente de $P$. frutescens é originada de óvulo anátropo, bitegumentado, crassinucelado. Com o desenvolvimento da semente, ocorre um aumento acentuado no número de estratos celulares, caracterizando-se a testa multiplicativa (Figura 4A-D). Na semente jovem, a exotesta, originada da epiderme externa do óvulo, possui cutícula fina e as células, com o desenvolvimento, começam a se alongar. A mesotesta é formada por várias camadas de células parenquimáticas de paredes finas, sendo que na primeira camada ocorrem idioblastos com cristais prismáticos. Feixes vasculares estão presentes na mesotesta.

\section{FIGURA 3. Fruto de Pseudima frutescens em seção transversal (A), com drusas (B) e um detalhe do feixe vascular (C)}

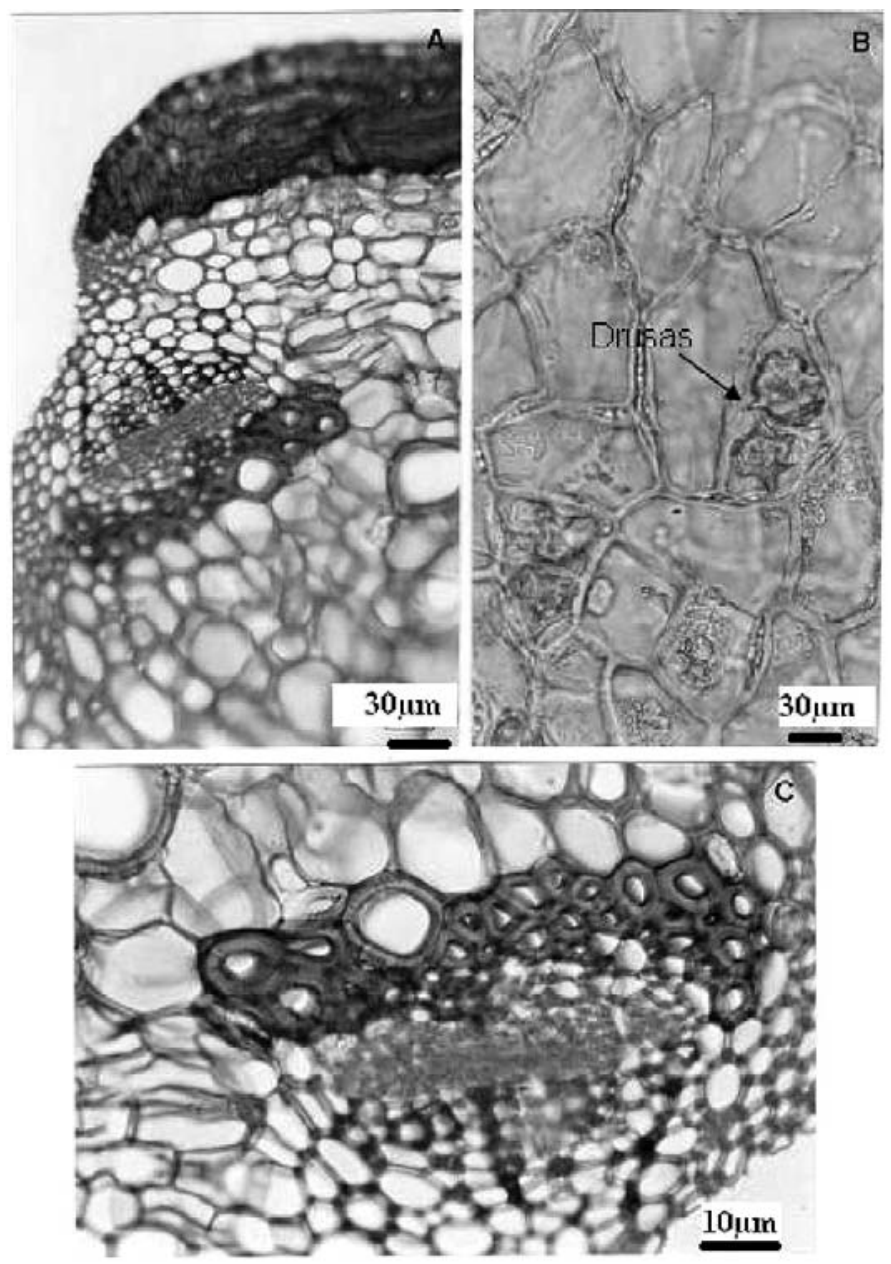

O tégmen apresenta-se constituído por várias camadas de células pequenas que vão sendo comprimidas com o desenvolvimento (Figura 4A-B). Na semente quase madura (Figura 4C-D), a testa é composta pela exotesta, com macroesclereídes alongadas de paredes bem espessadas na porção superior, e pela mesotesta que não sofre alterações com relação à semente jovem. O tégmen encontra-se quase totalmente comprimido. Esta estrutura não sofre alteração na semente completamente madura. 
FIGURA 4. Semente de Pseudima frutescens em seção transversal. A-B. Semente jovem. C-D. Semente madura.
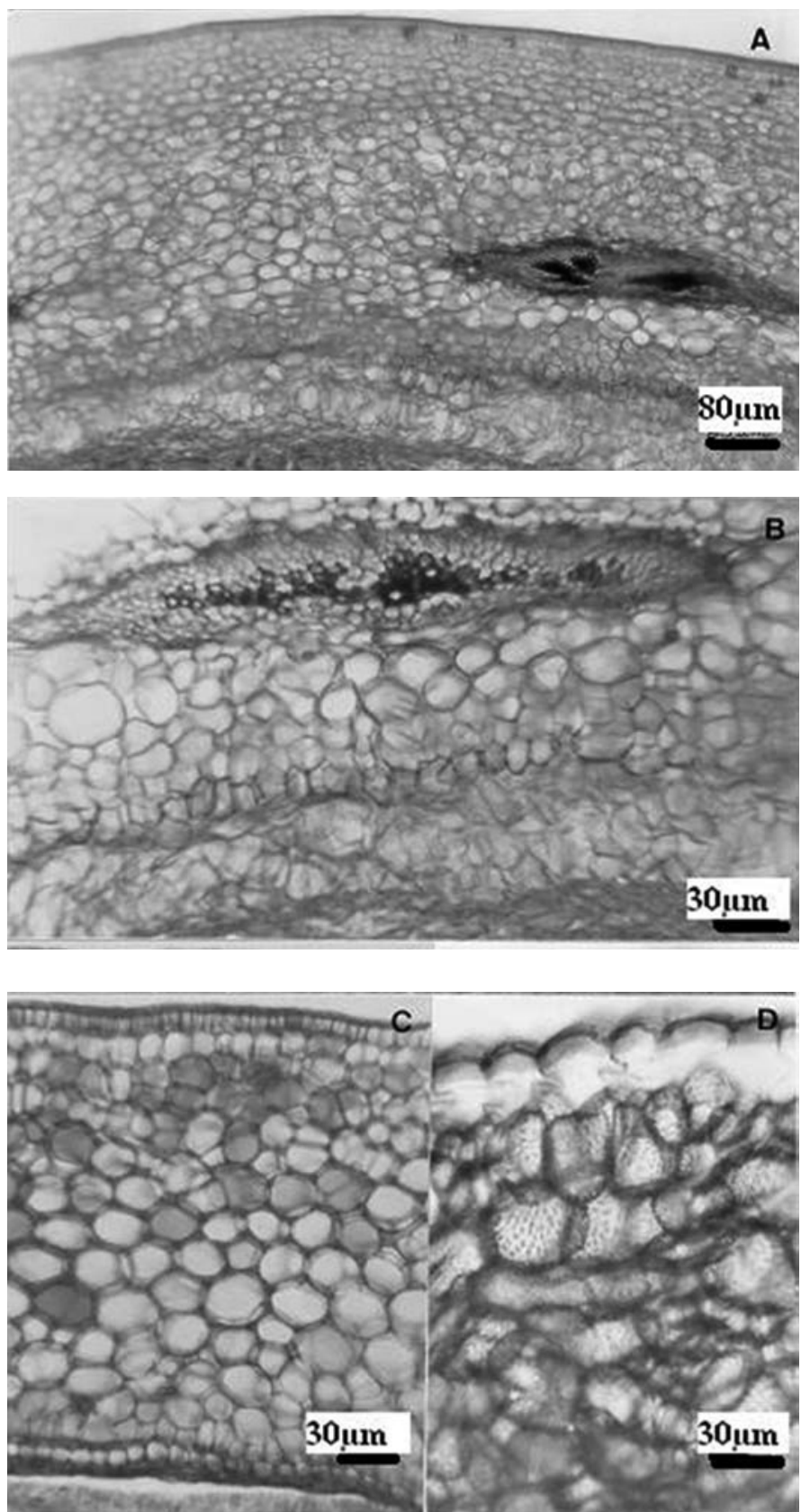

O embrião (Figuras 5A-B, 6A-C) é constituído pela protoderme, com células aproximadamente cubóides, de paredes delgadas e com um sistema procambial contínuo, rodeado pelo meristema fundamental, que é constituído por células de paredes finas. As células do embrião são totalmente preenchidas por grãos de aleurona e gotículas de óleo.
FIGURA 5. Embrião de Pseudima frutescens em seção longitudinal (A-B).
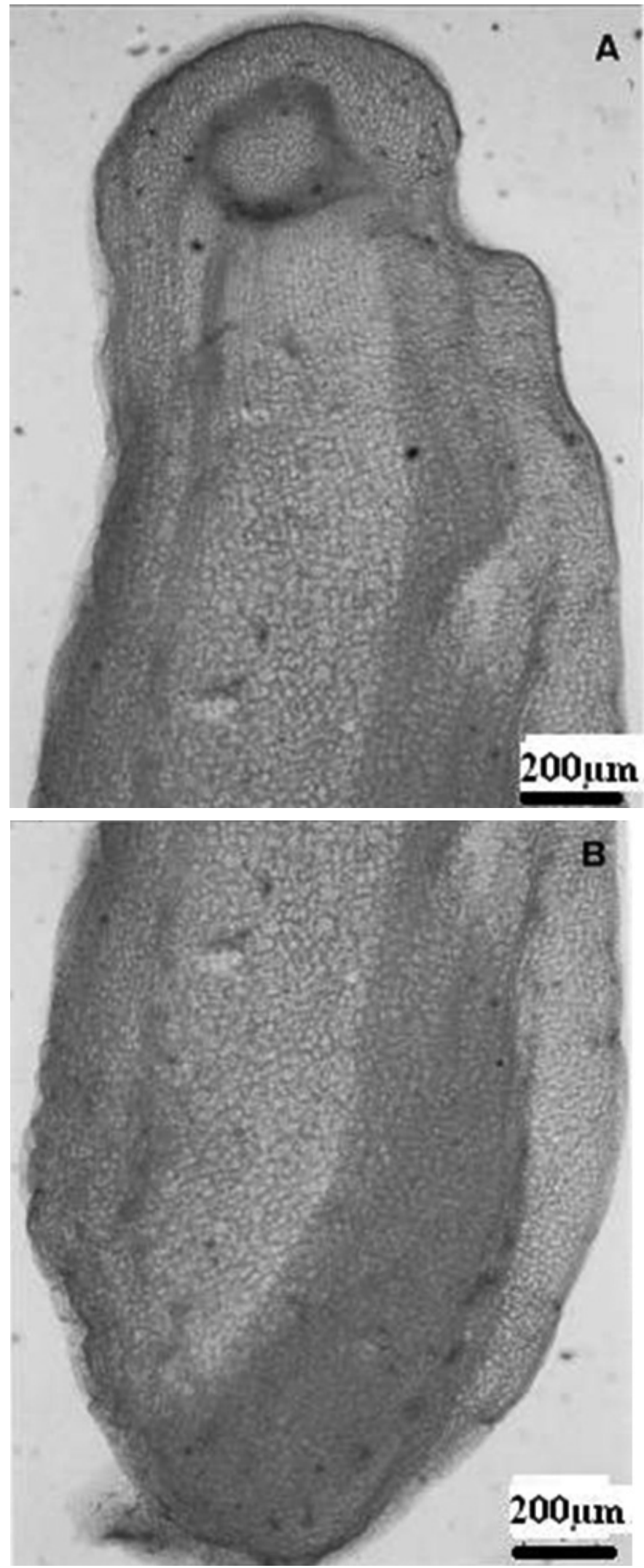
FIGURA 6. Embrião de Pseudima frutescens em seção transversal. A. Detalhe do eixo hipocótilo-radícula. B-C. Detalhe dos cotilédones.

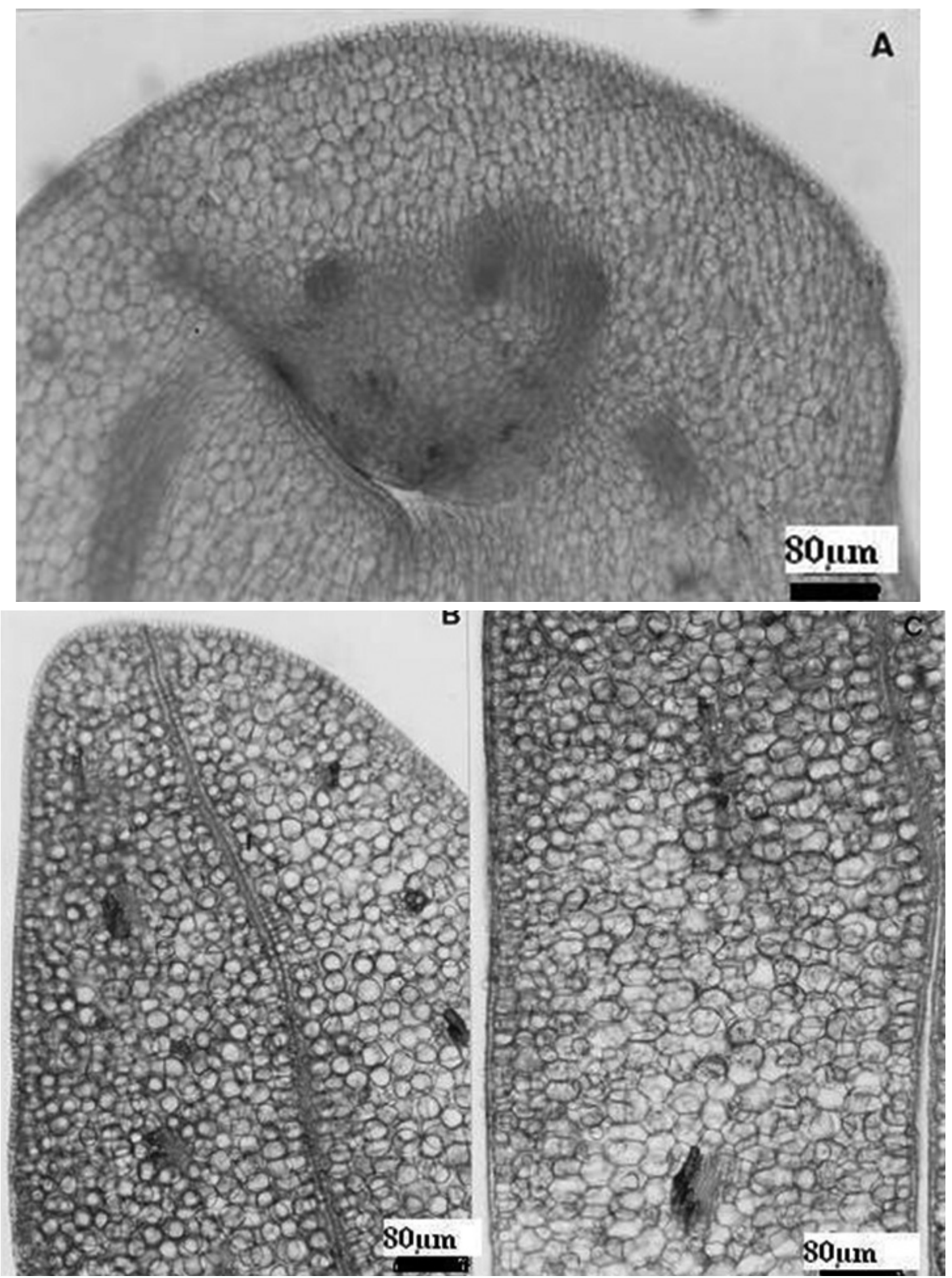

Corner (1976) descreveu a estrutura anatômica de vários gêneros de Sapindaceae, mas não fez nenhuma referência a Pseudima. De modo geral, muitas das características citadas para a família foram encontradas na semente de $P$. frutescens, como: sementes provenientes de óvulos anátropos, bitegumentados, crassinucelados, em geral dois por lóculo, 
semente preta, com testa crustácea e multiplicativa, arilada, exalbuminosa.

Com relação à germinação e ao desenvolvimento da plântula (Figura 7A-F), P. frutescens germina em presença de luz, sendo a germinação hipógea e a plântula criptocotiledonar, isto é, os cotilédones não se libertam do tegumento. A germinação teve início a partir de cinco dias, após a semeadura, iniciando com a protrusão da raiz primária axial, cilíndrica e esbranquiçada. Com oito dias, a raiz media $17 \mathrm{~mm}$ de comprimento, apresentando-se coberta de pêlos absorventes. Após 14 dias, o epicótilo (de coloração esverdeada) emergiu e, com 15 dias, a raiz primária da plântula media 50mm de comprimento, e possuía pilosidade menos abundante. $\mathrm{O}$ epicótilo (piloso) tinha $4 \mathrm{~mm}$ de comprimento e apresentava quatro catafilos. Após 30 dias, a plântula apresentava dois pares de eófilos, compostos, bifoliolados, expandidos, glabros, de formato oblongo-agudo, com base aguda, margem levemente sinuosa e venação peninérveabroquidódroma. Com 60 dias, a raiz principal estava com $12 \mathrm{~cm}$ de comprimento, exibindo muitas raízes laterais e o epicótilo tinha $9 \mathrm{~cm}$ de extensão e seis folhas expandidas.

FIGURA 7. Estádios de desenvolvimento da plântula de Pseudima frutescens (A-F).

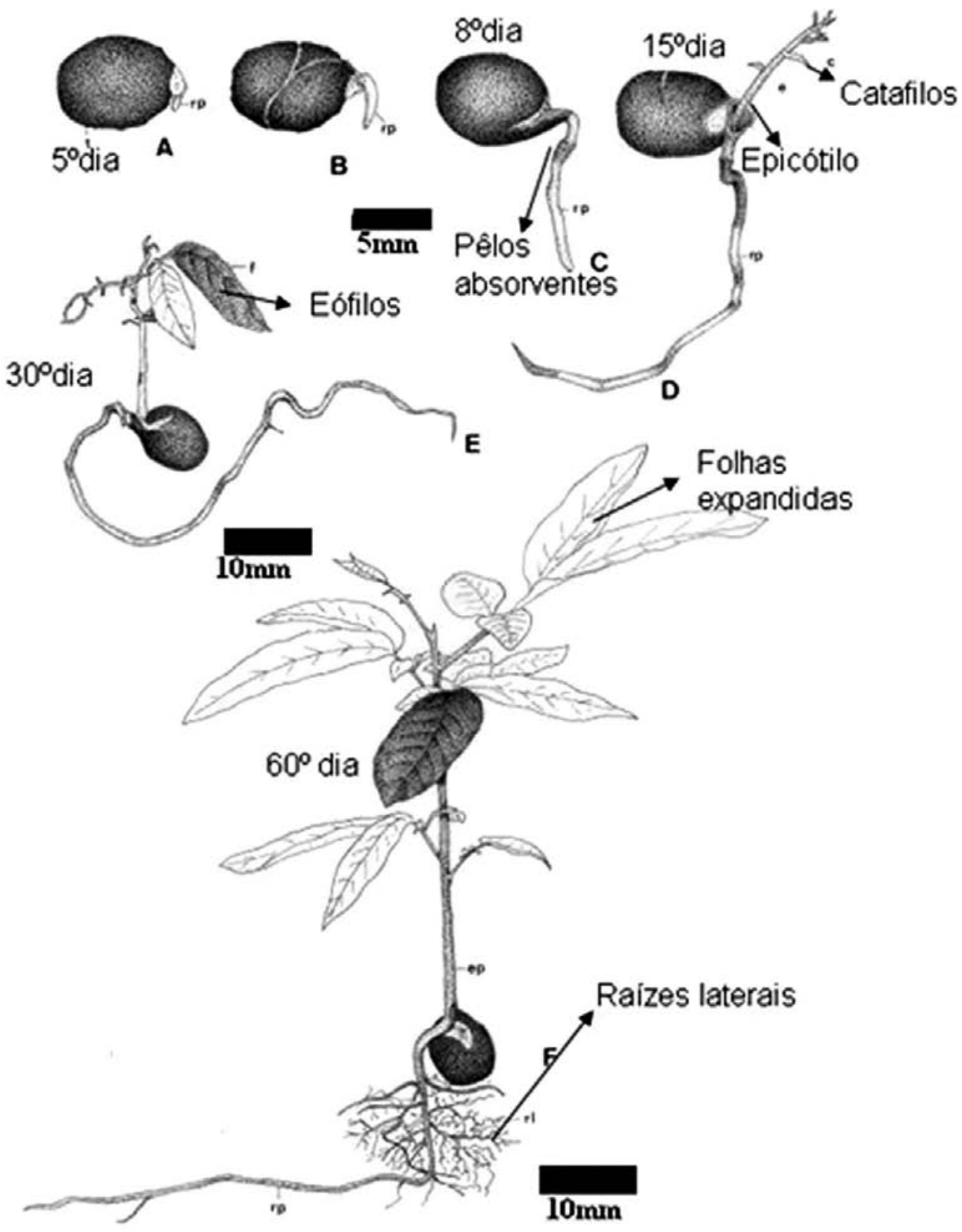


O tipo de germinação constitui um dos caracteres relevantes para diferenciar as espécies, enquanto o conhecimento morfológico da plântula permite caracterizar famílias, gêneros e até mesmo espécies, podendo ser aplicado em trabalhos de inventário e de manejo florestal. Estes estudos, além das descrições e ilustrações, fornecem informações valiosas sobre a morfologia, germinação, hábitat e identificação de muitas espécies em fases juvenis de crescimento, além de constituírem subsídios para a compreensão do ciclo biológico e da regeneração natural da espécie. No estudo taxonômico, podem fundamentar a sistemática de um grupo e oferecer caracteres auxiliares na interpretação filogenética (Duke, 1965).

As plântulas são estudadas por dois motivos básicos: a necessidade de identificação destas em certas regiões ou hábitats e por fornecerem informações adicionais ao conhecimento do ciclo de vida das plantas (Bokdam, 1977). Além disso, Rizzini (1965) afirmou que os caracteres morfológicos das plântulas podem ter significado ecológico e enfatizou que este conhecimento é importante para a melhor compreensão dos processos de germinação e desenvolvimento durante a regeneração natural da vegetação

Segundo Duke (1965), pode ocorrer uma seqüência característica no aparecimento dos eófilos de espécies que, quando adultas, apresentam folhas compostas. Este autor, citando várias famílias, inclusive Sapindaceae, relatou a possibilidade da ocorrência de uma seqüência abrupta, ou uma lenta e gradual. A seqüência lenta e gradual no aparecimento dos folíolos foi verificada em $P$. frutescens.

\section{CONCLUSÃO}

O fruto de $P$. frutescens, com duas sementes, é uma cápsula obcordada circundante, lobada, de coloração laranja-avermelhada externamente e laranja internamente. A semente, exalbuminosa, é ovóide, preta e brilhante. A plântula é criptocotiledonar e a germinação, que é hipógea, inicia-se no quinto dia após a semeadura. A espécie tem desenvolvimento relativamente rápido, podendo ser indicada para os programas de reflorestamento.

\section{AGRADECIMENTOS}

Ao Conselho Nacional de Desenvolvimento Científico e Tecnológico (CNPq) e à Coordenação de Aperfeiçoamento de Pessoal de Nível Superior-CAPES pelo auxílio à pesquisa. Somos gratos também aos revisores anônimos que contribuíram para a melhoria da versão inicial deste trabalho.

\section{REFERÊNCIAS}

BARROSO, G.M.; MORIM, M.P.; PEIXOTO, A.L.; ICHASO, C.L.F. Frutos e sementes: morfologia aplicada à sistemática de dicotiledôneas. Viçosa: Editora UFV, 1999. 443p.

BELTRATI, C.M. Morfologia e anatomia de sementes. Rio Claro: Departamento de Botânica da UNESP, 1994. 108p. Apostila do curso de Pós-Graduação em Biologia Vegetal

BOKDAM, J. Seedlings morphology of some African Sapotaceae and its taxonomical significance. Mededelingen Landbouwhogeschool Wageningen, The Netherlands, v.77, n.20, p.1-84, 1977.

BRAVATO, M. Estudio morfologico de frutos y semillas de las Mimosoideae (Leguminosae) de Venezuela. Acta Botanica Venezuelica, Caracas, v.9, n.1/4, p.317-361, 1974.

CORNER, E.J.H. The seeds of Dicotyledons. Cambridge: Cambridge University Press, 1976. 558p.

DUKE, J.A. Keys for the identification of seedling of some prominent woody species in eight forest types in Puerto Rico. Annals of the Missouri Botanical Garden, St. Louis, v.52, n.3, p.314-50, 1965.

FEDER, N.; O’BRIEN, T.P. Plant microthecnique: some principles and new methods. American Journal of Botany, Columbus, v.55, n.1, p.123-142, 1968.

FINGER, Z. Estudos sobre a identificação dendrológica da regeneração natural de algumas espécies na Microregião de Viçosa, Minas Gerais. 1977. 92 f. Dissertação (Mestrado em Ciência Florestal) - Universidade Federal de Viçosa, Viçosa.

GOMES, J.M.; COUTO, L.; BORGES, R.C.G.; FONSECA, E.P. Efeito de diferentes substratos na produção de mudas de Eucalyptus grandis W.Hill ex Maiden, em "Win-Strip". Revista Árvore, Viçosa, v.15, n.1, p.35-42, 1991.

GUERRITS, P.O. The application of glycolmethacrylate in histiotechnology: some fundamental principles. Gröningen, Netherlands: Department of Anatomy and Embriology, 1991. 80p

GUNN, C.R. Seed collecting and identification. In: KOZLOWSKI, T.T. Seed biology. New York: Academic Press, 1972. v.3. p.55-143.

LORENZI, H. Árvores brasileiras: manual de identificação e cultivo de plantas arbóreas nativas do Brasil. Nova Odessa: 
Plantarum, 1992. 352p.

MILANEZE, M.A. Influência da intensidade luminosa e do fotoperíodo no desenvolvimento inicial de Pseudolaelia vellozicola (Hohene) Porto \& Brade, a partir de sementes selecionadas por densidade. 1992. 129 f. Dissertação (Mestrado em Biologia Vegetal) - Instituto de Biociências, Universidade Estadual Paulista, Rio Claro.

NACIF, S.R.; PAOLI, A.A.S.; SALOMÃO, L.C.C. Morphological and anatomical development of the litchi fruit (Litchi chinensis Sonn. Cv. Brewster). Fruits, Paris, v.56, n.4, p.225-233, 2001.

OLIVEIRA, A.K.M.; SCHLEDER, E.J.; FAVERO, S. Caracterização morfológica, viabilidade e vigor de sementes de Tabebuia aurea (Silva Manso) Benth. \& Hook. f. ex. S.Moore. Revista Árvore, Viçosa, v.30, n.1, p.25-32, 2006.

PAOLI, A.A.S.; SARTI, J. Morfoanatomia e desenvolvimento de frutos e sementes de Dodonea viscosa (L.) Jacquin. Revista Brasileira de Sementes, Pelotas, v.30, n.1, 2008. No prelo

RAVEN, P.H.; EVERT, R.F; EICHHORN, S.E. Biologia vegetal. 6.ed. Rio de Janeiro: Guanabara Koogan S.A., 2001. 906p.

REITZ, R. Flora ilustrada catarinense. Itajaí: Herbário Barbosa Rodrigues, 1980. 132p.

RICARDI,M.;TORRES,F.,HERNÁNDEZ,C.,QUINTERO, R. Morfologia de plantulas de arboles venezolanos. I. Revista Florestal Venezolana, Mérida, v.27, p.15-56, 1977.

RIZZINI, C.T. Experimental studies on seedling development of cerrado wood plants. Annals of the Missouri Botanical Garden, St. Louis, v.52, n.3, p.410-426, 1965.

ROOSMALEN, M.G.M. Fruits of the Guianan flora. Utrecht: Institute of Systematic Botany, 1985. 483p.

ROTH, I. Fruits of Angiosperms. Stuttgart: Gebruder Borntraeger, 1977. 675p.

SCHULTZ, A.R.H.. Introdução à Botânica Sistemática. 5.ed. vol. 2. Porto Alegre: Editora da UFRGS, 1985. 414p.

SPJUT, R.W. A systematic treatment of fruit types. Memoirs of the New York Botanical Garden, New York, v.70, p.1182, 1994.

TORRES, E.B. Identificacion de plantulas de algunas especies arboreas del bosque de Niebla. Perez-Arbelaezia, Bogotá, v.1, n.1, p.39-95, 1985. 